\title{
ПРИОРИТЕТЫ ИННОВАЦИОННОГО РАЗВИТИЯ ОТСТААЫХ РЕГИОНОВ ЮГА РОССИИ
}

\begin{abstract}
Аннотауия. Цель работы. В статье рассматривается проблема несбалансированного

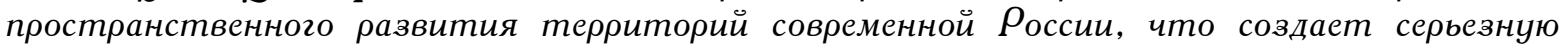
угрозу государственной безопасности и непосредственно связано с неоправданно высокой степенью различия регионов по основным сочиально-экономическим показателям и наличием в стране большого числа отсталых регионов. Разработанная правительством

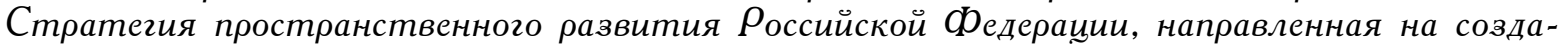
ние макрорегионов так называемых центров (полюсов) экономического роста, не решает проблем развития экономически отсталых национальных республик. На наш взгляд, при разработке и реализации стратегии пространственного развития необходимо учитывать существующую взаимосвязь экономической отсталости южных национальных регионов $Р Ф$ и закономерностей их инновационного (научно-технического) развития. Метод или методология проведения работы. Проведен анализ стратегических документов пространственного развития территорий современной

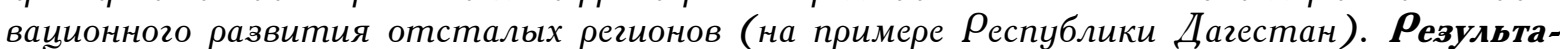
ты. Определены приоритеты инновационного развития отсталых регионов юга России: формирование региональной инновационной системы, укрепление инновационного потенциала, уход от произвольного административного вмешательства в экономику, снятие институциональных барьеров модернизации, реализация кластерного подхода на региональном уровне. Выводы. Отсталым в экономическом плане регионам для достижения среднероссийского уровня необходимо существенное увеличение темпов роста основных

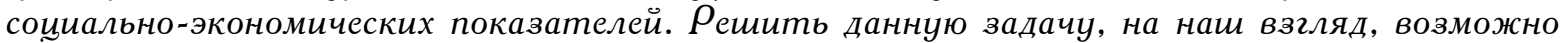
путем формирования новой кониепиии инновационного развития. Делается вывод о том, что в настоящее время в рамках расширения использования проектных методов управления социально-экономическим развитием необходим более явный акиент на стимулирование инновационной активности. Поддержка инноваций должна стать одним из приоритетов в политике регионального правительства.
\end{abstract}

Ключевые слова: регион, инновационное развитие, промышленность, конкуренция, модернизащия, стратегия пространственного развития.

IDZIEV GADZHIMURAD IDZIEVICH

Dr.Sc. of Economics, leading researcher At the Institute of socio-economic research of the Russian Academy of Sciences, e-mail:textima@mail.ru

\section{PRIORITIES OF INNOVATIVE DEVELOPMENT BACKWARD REGIONS OF SOUTHERN RUSSIA}

Abstract. Purpose of work. The article deals with the problem of unbalanced spatial development of the territories of modern Russia, which creates a serious threat to state security and is directly related to the unjustifiably high degree of regional differences in the main socio-economic indicators and the presence of a large number of backward regions in the country. The strategy of spatial development of the Russian Federation developed by the government, aimed at creating macro-regions of the so-called centers ( $\rho$ oles) of economic growth, does not solve the problems of development of economically backward national republics. In our opinion, when developing and implementing a spatial development strategy, it is necessary to take into account the existing relationship between the economic backwardness of the southern national regions of the Russian Fed- 
eration and the patterns of their innovative (scientific and technical) development. Method or methodology of the work. The analysis of strategic documents of spatial development of territories of modern Russia and patterns of innovative development of backward regions (on the example of the Republic of Dagestan) is carried out. Results. Priorities of innovative development of backward regions of the South of Russia are defined: formation of a regional innovation system, strengthening of innovative potential, avoiding arbitrary administrative interference in the economy, removal of institutional barriers to modernization, implementation of the cluster approach at the regional level. Conclusions. Economically backward regions need a significant increase in the growth rate of the main socio-economic indicators in order to reach the national average. In our opinion, it is possible to solve this problem by forming a new concept of innovative development. It is concluded that at present, in the framework of expanding the use of project methods for managing socio-economic development, a more explicit focus on stimulating innovation activity is needed. Support for innovation should be one of the priorities in the regional government's policy. Keywords: region, innovative development, industry, competition, modernization, spatial development strategy.

Введение. Сегодня основной задачей ученых, занимающихся изучением тенденций и векторов пространственного развития современной России, является необходимость выявления и конкретизации внутрирегиональных факторов и потенциальных возможностей интенсификации экономического развития. Распад Союза и развал плановой экономики привел к разрыву технологических, экономических, логистических и других цепочек, вследствие чего в стране появились проблемные и депрессивные регионы. В этих условиях необходима более осознанная и активная государственная политика, касающаяся решения возникающих экономических проблем в регионах. И начать надо, по нашему мнению, с решения стратегических проблем пространственного развития, основной из которых, в частности, является преодоление отсталости и депрессивности отдельных регионов.

Проблемы несбалансированного пространственного развития территорий современной России создают серьезную угрозу государственной безопасности и непосредственно связаны с неоправданно высокой степенью различия регионов по основным социально-экономическим показателям: валовый региональный продукт на душу населения, денежные доходы, среднемесячная начисленная заработная плата, инвестиции в основной капитал $[4,8,10]$. Ситуация усугубляется наличием в стране большого числа отсталых регионов, что наглядно видно из доклада аналитического центра при Правительстве России, в котором на основе синтетической классификации выделяются 9 групп регионов - от финансово-экономических центров до менее развитых аграрных, куда попадает большинство устойчиво депрессивных регионов СКФО [11].

Методология. Сегодня активно обсуждается разработанная Правительством РФ «Стратегия пространственного развития Российской Федерации на период до 2025 г.», которая могла бы сделать более осмысленной государственную политику, связанную с благосостоянием населения и устойчивостью функционирования государства. По задумке авторов этого, несомненно, важного и необходимого в современной России документа: «Основным направлением пространственного развития является полицентрическое развитие, направленное на увеличение числа центров экономического роста, обладающих конкурентоспособной экономикой, а также обеспечение высокой связанности таких центров между собой, с прилегающими территориями и пунктами выхода на международные рынки» ${ }^{1}$.

По мнению экономиста Михаила Дмитриева, итогом реализации данной стратегии «к 2035 г. в России должны появиться 37 новых полюсов роста - городские агломерации, агролесопромышленные и минерально-сырьевые зоны, вместе они обеспечат до 65 процентов экономического роста страны» (рис.).

\footnotetext{
${ }_{1}^{1}$ Проект Стратегии пространственного развития Российской Федерации. - URL : https://www.spsss.ru/assets/ files/2018/v-nts_strategiya-prostranstvennogo-razvitiya.pdf.
} 
ИДЗИЕВ Г.И.

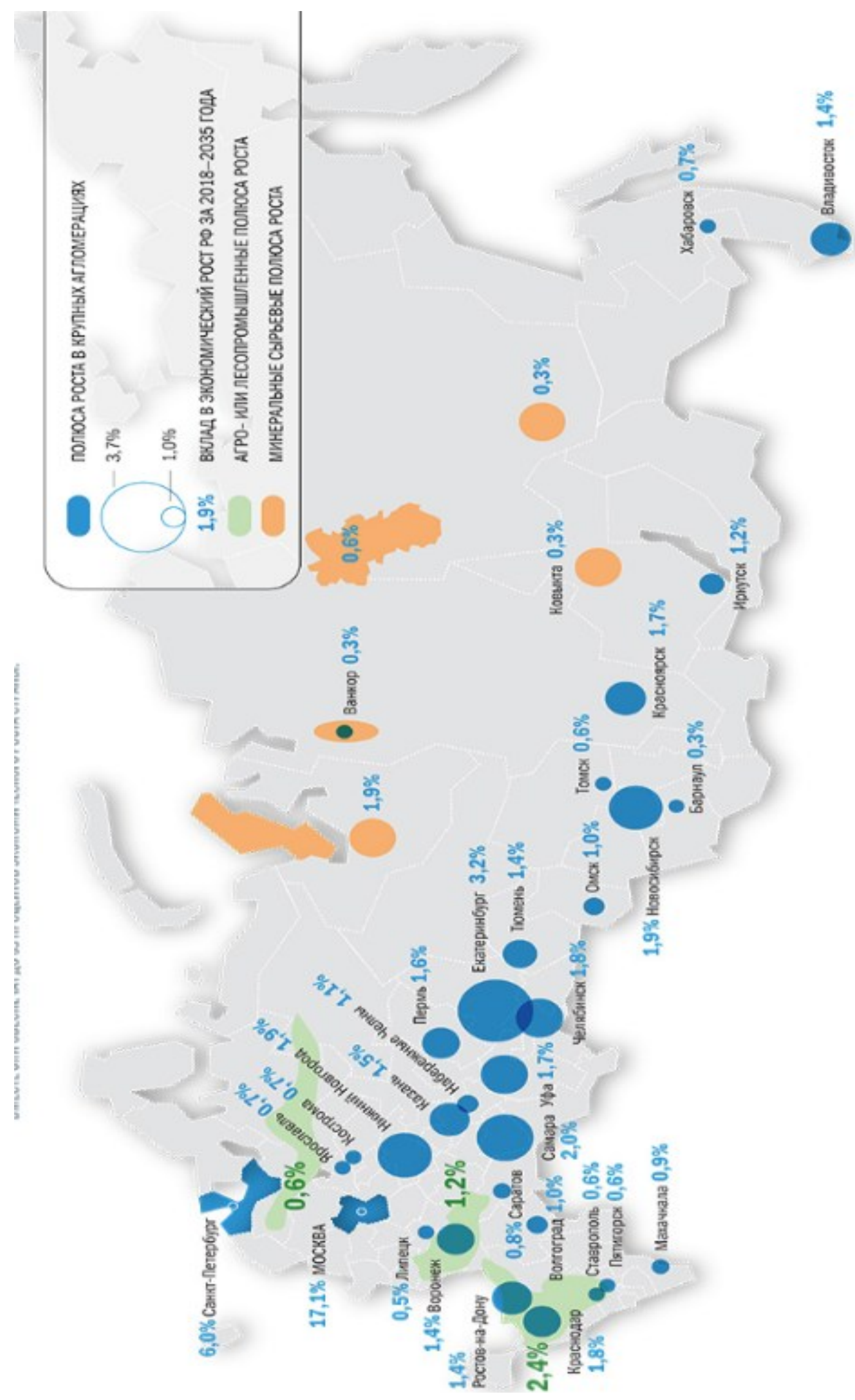

Рис. 1. Полюсы роста и их вклад в экономический рост РФ за 2018-2035 г2.

Источник: Дмитриев М. Где искать новый рост? // Огонёк"№14 om 15.04.2019. С. 12. - URL : https:// www.kommersant.ru/doc/3938485. 
Идеологическая направленность Стратегии пространственного развития Российской Федерации на создание макрорегионов так называемых центров (полюсов) экономического роста, на наш взгляд, не решает проблем развития экономически отсталых периферийных национальных регионов и, по сути, представляет собой перечень и укрупненную схему размещения подлежащих созданию (модернизации) объектов инфраструктуры федерального значения.

На наш взгляд, при разработке и реализации стратегии пространственного развития необходимо учитывать существующую взаимосвязь экономической отсталости периферийных национальных регионов РФ и закономерностей их инновационного (научно-технического) развития. В частности, в Республике Дагестан изменившаяся структура экономики региона, снижение доли промышленного производства в ВРП, а также существенное ослабление экономики во многом явились следствием падения производства на крупных предприятиях. Проблема усугубляется тем, что в большинстве нормативных документов Министерства экономического развития РФ, в Концепции долгосрочного социально-экономического развития РФ на период до 2020 г., а также в разрабатываемой Стратегии социально-экономического развития Республики Дагестан до 2035 г. республике отводится роль удаленного от центра, аграрноориентированного региона. Вследствие чего многие программы развития регионального промышленного сектора не получают должной поддержки, что усугубляет степень его проблемности и в дальнейшем чревато еще большим отставанием в социально-экономическом развитии, ростом дотационности и снижением благосостояния населения.

Результаты. Сегодня в рейтинге регионов страны по основным показателям социальноэкономического развития Республика Дагестан продолжает оставаться отстающим, устойчиво депрессивным регионом России. Если сравнивать со Ставропольским краем, то при сравнимых показателях численности населения, валовому региональному продукту на душу населения и основным фондам в экономике по остальным показателям наблюдается существенное отставание, особенно в обрабатывающих производствах [7].

Рассматривая динамику отраслевой структуры экономики Дагестана можно констатировать, что промышленность этой республики до сих пор не вышла из кризиса после глубокого спада производства с начала 90-х гг. прошлого столетия. По сравнению со Ставропольским краем наблюдается кратное отставание объемов промышленной продукции по всем видам экономической деятельности: добыча полезных ископаемых, обрабатывающие производства, обеспечение электрической энергией, газом и паром, водоснабжение, водоотведение, организация сбора и утилизации отходов, а также данных показателей в расчете на душу населения (табл.).

\section{Таблиияа}

Объем промышленной продукции Республики Дагестан в сравнении со Ставропольским краем по видам экономической деятельности (на душу населения, руб.)*

\begin{tabular}{|c|c|c|c|c|c|}
\hline \multirow{2}{*}{ Виды экономической деятельности } & \multicolumn{2}{|c|}{ РД } & \multicolumn{2}{|c|}{ Ставропольский край } & \multirow{2}{*}{$\begin{array}{c}\text { Отношение } \\
\text { Став. край к РД, } \\
2017 \text { г. } \\
\end{array}$} \\
\hline & 2016 г. & 2017 г. & 2016 г. & 2017 г. & \\
\hline Добыча полезных ископаемых & 1288 & 1608 & 3258 & 3807 & 2,4 раз \\
\hline $\begin{array}{l}\text { Обрабатывающие } \\
\text { Производства }\end{array}$ & 10606 & 13254 & 97935 & 93647 & 7,1 раз \\
\hline $\begin{array}{l}\text { Обеспечение электрической энергией, } \\
\text { газом и паром }\end{array}$ & 5631 & 6312 & 26839 & 29630 & 4,7 раз \\
\hline $\begin{array}{l}\text { Водоснабжение; } \\
\text { водоотведение, организация сбора и } \\
\text { утилизации отходов }\end{array}$ & 771 & 858 & 3412 & 3597 & 4,2 раз \\
\hline
\end{tabular}

*Источник: Регионы России. Сочиально-экономические показатели. 2018 г.

Возможно, такое положение дел связано с недостаточным инновационным потенциалом Дагестана и неспособностью к модернизации.

Потенциально Дагестан является чрезвычайно благоприятным регионом для притока капиталов и имеет существенные конкурентные преимущества по группе факторов, способных 
оказать воздействие на улучшение структуры региональной экономики. К ним относятся:

1. Выгодное геополитическое положение. Республика является естественным мостом между Россией и странами Юго-Восточной Азии.

2. Ресурсный потенциал: богатая природно-сырьевая база, относительно низкие цены на сырье, топливо, рекреационные ресурсы. Относительно дешевые и квалифицированные трудовые ресурсы.

3. Наличие производственного потенциала, который, с одной стороны, избыточный, с другой стороны, не хватает мощностей по производству конкурентоспособной, высококачественной продукции [6].

4. Возможность освоения новых рынков сбыта внутри региона, Российская Федерация, страны ближнего зарубежья.

В то же время использование этого потенциала серьезно ограничено политическими, экономическими (в частности, институциональными), криминальными, социальными рисками. Для достижения регионом среднероссийского уровня необходимо существенное увеличение темпов роста основных социально-экономических показателей, особенно, по промышленным видам деятельности. Решить данную задачу, на наш взгляд, возможно путем формирования новой концепции инновационного развития.

Необходимость формирования новой концепции инновационного развития в качестве приоритета региональной экономической политики является все более очевидной. В этом вопросе существует острая потребность не только в определении четких стратегических ориентиров для открытой экономики, имеющей гетерогенный характер и значительный накопленный интеллектуальный капитал, но и в тактике их достижения. Необходимо формирование нового подхода к системе, формирование альянса на региональном и федеральном уровнях, создаваемого под достижение вполне конкретных стратегических целей. Необходимо формирование сети между региональными командами профессиональных менеджеров, а также координация их действий в рамках всего экономического пространства. Необходимо формирование новой высокопрофессиональной элиты. Только в этом случае, на смену старой системе будет постепенно, в процессе замещения, приходить новая, более здоровая и более конкурентоспособная система. Конкурентоспособность сегодня называют основным источником устойчивого экономического роста. Ее основой, в свою очередь, является инновационная активность бизнеса. Успех, особенно глобальный, во все большей степени обусловлен обновлением технологий, освоением новых рыночных ниш и организационными нововведениями (которые принято называть институциональными инновациями) [4].

В настоящее время в рамках расширения использования проектных методов управления социально-экономическим развитием необходим более явный акцент на стимулировании инновационной активности. Поддержка инноваций должна стать одним из приоритетов в политике республиканского правительства.

\section{Приоритеты инновачионного развития экономики региона}

Для развития региональной инновационной системы необходимо обеспечить синхронизацию, сбалансированность различных аспектов инновационного развития региона, увеличить объем затрат предпринимательского сектора на исследования и разработки, повысить координацию инновационных проектов с соседними регионами и зарубежными государствами.

Дальнейшее укрепление инновационного потенциала, развитие инновационной деятельности, использование современных достижений науки и высоких технологий позволит осуществить структурную диверсификацию, перевести экономику региона на инновационную модель развития и в долгосрочной стратегической перспективе обеспечить ее конкурентоспособность на региональном, российском и мировом рынках. Этому должны способствовать меры по модернизации всей научно-образовательной сферы, созданию республиканской инновационной системы, научно-образовательного центра мирового уровня и т.д.

Важным принципом инновационного развития является прозрачность, когда любая деятельность всех участников хозяйства и на всех ее этапах понятна и легко поддается объяснению с точки зрения соответствия установленным правилам. Построение инновационной системы невозможно без создания эффективной институциональной среды, которая стимулирует инновационную деятельность и защищает ее с помощью надежного механизма санкций. 
Существует проблема замены произвольного административного вмешательства в экономику, тесно связанного с высоким уровнем коррупции, в государственное регулирование, осуществляемое в строгих правовых рамках. До сих пор основные хозяйственные институты государства представляют собой не столько институты экономического и социального регулирования в целях развития, сколько инструмент фискального обслуживания государственного аппарата.

Существуют институциональные барьеры модернизации, определяемые неэффективной институциональной структурой бизнеса. Произошел значительный рост транзакционных издержек, приведший к значительному перераспределению добавленной стоимости в пользу торгово-посреднического сектора, причем это перераспределение не ограничилось лишь начальным этапом рыночных реформ, когда происходило формирование новой рыночной инфраструктуры.

Существенным шагом в повышении инвестиционной привлекательности и стимулировании социально-экономического развития региона, его инновационного развития может стать реализация кластерного подхода на региональном уровне, например, путем создания интегрированных агропромышленных кластеров. Такое значимое увеличение масштабов объектов, привлекательных с точки зрения инвестирования, позволит качественно улучшить инвестиционный климат региона. Создание кластеров должно опираться на всестороннюю оценку конкурентных преимуществ региона, его природно-климатических условий, сложившуюся структуру производства и специализацию в агропромышленных связях.

\section{Литература}

1. Абдулаев, Ш. С. О., Садыкова, А. М. Инноваџионное развитие субъектов РФ как основа формирования производительных сил // Вопросы структуризаиии экономики. 2013. № 4. С. 51-53.

2. Ахмедуев, А. Ш. Механизмы государственного регулирования инвестиционной деятельности в Республике Дагестан // Региональные проблемы преобразования экономики. 2016. № 2. С. 76-84.

3. Багомедов, М. А. Формирование сочиильно-экономической политики в проблемных регионах в условиях модернизации общественных отношений // Вопросы структуризации экономики. 2014. № 1. С. 184188.

4. Бахтизин, А. Р., Бухвальд, Е. М., Кольчугина, А. В. Выравнивание регионов в России : иллюзии программы и реалии экономики // Вестник Института экономики Российской академии наук. 2016. № 1. С. 76-91.

5. Гасанов, М. А., Омаров, А. 3., Магомедов, А. Г. Исследование теоретических основ развития экономики региона на основе инновационных преобразований // Транспортное дело России. 2014. № 1. С. 232234.

6. Дохолян, С. В., Петросянц, В. З., Садыкова, А. М. Современные проблемы инновационного социальноэкономического развития региона // Региональные проблемы преобразования экономики. 2012. № 3. С. 43-51.

7. Идзиев, Г. И. Политика промышленного возрождения в условиях устойчиво депрессивного региона России // ЭТАП: экономическая теория, анализ, практика. 2019. № 3. С. 59-73.

8. Климанов, В. В., Будаева, К. В. Точки роста как элемент стратегического планирования в регионах России // Региональные исследования. 2017. № 3 (57). С. 99-106.

9. Кузнецова, О. В. Экономическое развитие регионов : теоретические и практические аспекты государственного регулирования. М. : Ленанд, 2015.

10. Лексин, В. Н., Швеиов, А. Н. Реформы и регионы : системный анализ проиессов реформирования региональной экономики, становления федерализма и местного самоуправления. - М. : Ленанд, 2012.

11. Петросяни, В. З., Дохолян, С. В., Деневизюк, Д. А. Проблемные регионы : экономическая политика в условиях федерализма // Проблемы развития национальной экономики в условиях глобальных инновационных преобразований : материаль всероссийской научно-практической конферениии ; под ред. Казиевой Ж.Н. 2018. С. 7-22.

12. Сагидов, Ю. Н., Дохолян, С. В., Кутаев, Ш. К. Крупные промышленные предприятия как активизаторы развития отрасли и экономики региона (на примере Республики Дагестан) // Региональные проблемы преобразования экономики. 2015. № 4 (54). С. 11-18.

13. Селезнев, А. 3. Инновационная концепщия конкурентных преимуществ // Феномен рыночного хозяйства : векторы и особенности эволючии. - М. : LSP, 2017. С. 220-230.

14. Хрусталёв, Е. Ю., Хрусталёв, О. Е. Методология оиенки отраслевых темпов и стабильности инновационного развития наукоемких предприятий и организаций // Экономический анализ : теория и практика. 2014. № 10 (362). C. 2-15.

15. Batkovsky, A. M., Fomina, A. V., Semenova, E. G., Khrustalev, E. Yu., Khrustalev, O. E. Models and methods for evaluating operational and financial reliability of high-tech enterprises // Journal of Applied Economic Sciences. 2016. T. 11. No. 7. P. 1384-1394.

16. Bukhvald, E. M. The strategy for development of small and medium entrepreneur-ship in Russia till 2030 ambitions and realities // Economic and Social Changes : Facts, Trends, Forecast. 2016. No. 1 (43). P. 66-80. 
ИДЗИЕВ Г.И.

ПРИОРИТЕТЫ ИННОВАЦИОННОГО РАЗВИТИЯ ОТСТАЛЫХ РЕГИОНОВ ЮГА РОССИИ

17. Gadziev, N. G., Rabadanov, M. H., Eldarov, E. M., Idziev, G. I. Development of industrial enterprises investment policy of Dagestan Republic // Ponte. 2017. Vol. 73. Is. 10. P. 317-325.

18. Tregenna, F. Manufacturing Productivity, Deindustrialization and Reindustrialization // UNU-WADER Working Paper. 2011. No. 57.

\section{References:}

1. Abdulaev, SH. S. O., Sadykova, A. M. Innovacionnoe razvitie subëktov RF kak osnova formirovaniya proizvoditel'nyh sil // Voprosy strukturizacii ekonomiki. 2013. № 4. S. 51-53.

2. Ahmeduev, A. SH. Mekhanizmy gosudarstvennogo regulirovaniya investicionnoj deyatel'nosti v Respublike Dagestan // Regional'nye problemy preobrazovaniya ekonomiki. 2016. № 2. S. 76-84.

3. Bagomedov, M. A. Formirovanie social'no-ekonomicheskoj politiki v problemnyh regionah v usloviyah modernizacii obshchestvennyh otnoshenij // Voprosy strukturizacii ekonomiki. 2014. № 1. S. 184-188.

4. Bahtizin, A. R., Buhval'd, E. M., Kol'chugina, A. V. Vyravnivanie regionov v Rossii : illyuzii programmy $i$ realii ekonomiki // Vestnik Instituta ekonomiki Rossijskoj akademii nauk. 2016. № 1. S. 76-91.

5. Gasanov, M. A., Omarov, A. Z., Magomedov, A. G. Issledovanie teoreticheskih osnov razvitiya ekonomiki regiona na osnove innovacionny preobrazovanij // Transportnoe delo Rossii. 2014. № 1. S. 232-234.

6. Doholyan, S. V., Petrosyanc, V. Z., Sadykova, A. M. Sovremennye problemy innovacionnogo social'noekonomicheskogo razvitiya regiona // Regional'nye problemy preobrazovaniya ekonomiki. 2012. № 3. S. 4351 .

7. Idziev, G. I. Politika promyshlennogo vozrozhdeniya v usloviyah ustojchivo depressivnogo regiona Rossii // ETAP: ekonomicheskaya teoriya, analiz, praktika. 2019. № 3. S. 59-73.

8. Klimanov, V. V., Budaeva, K. V. Tochki rosta kak element strategicheskogo planirovaniya v regionah Rossii // Regional'nye issledovaniya. 2017. № 3 (57). S. 99-106.

9. Kuznecova, O. V. Ekonomicheskoe razvitie regionov : teoreticheskie i prakticheskie aspekty gosudarstvennogo regulirovaniya. M. : Lenand, 2015.

10. Leksin, $V$. . N., SHvecov, A. N. Reformy i regiony : sistemnyj analiz processov reformirovaniya regional'noj ekonomiki, stanovleniya federalizma i mestnogo samoupravleniya. - M. : Lenand, 2012.

11. Petrosyanc, V. Z., Doholyan, S. V., Denevizyuk, D. A. Problemnye regiony : ekonomicheskaya politika $v$ usloviyah federalizma // Problemy razvitiya nacional'noj ekonomiki v usloviyah global'nyh innovacionnyh preobrazovanij : materialy vserossijskoj nauchno-prakticheskoj konferencii; pod red. Kazievoj ZH.N. 2018. S. 7-22.

12. Sagidov, YU. N., Doholyan, S. V., Kutaev, SH. K. Krupnye promyshlennye predpriyatiya kak aktivizatory razvitiya otrasli i ekonomiki regiona (na primere Respubliki Dagestan) // Regional'nye problemy preobrazovaniya ekonomiki. 2015. № 4 (54). S. 11-18.

13. Seleznev, A. Z. Innovacionnaya koncepciya konkurentnyh preimushchestv // Fenomen rynochnogo hozyajstva : vektory i osobennosti evolyucii. - M. : LSP, 2017. S. 220-230.

14. Hrustalyov, E. YU., Hrustalyov, O. E. Metodologiya ocenki otraslevyh tempov i stabil'nosti innovacionnogo razvitiya naukoemkih predpriyatij i organizacij // Ekonomicheskij analiz : teoriya i praktika. 2014. № 10 (362). S. $2-15$.

15. Batkovsky, A. M., Fomina, A. V., Semenova, E. G., Khrustalev, E. Yu., Khrustalev, O. E. Models and methods for evaluating operational and financial reliability of high-tech enterprises // Journal of Applied Economic Sciences. 2016. T. 11. No. 7. P. 1384-1394.

16. Bukhvald, E. M. The strategy for development of small and medium entrepreneur-ship in Russia till 2030 : ambitions and realities // Economic and Social Changes : Facts, Trends, Forecast. 2016. No. 1 (43). P. 66-80.

17. Gadziev, N. G., Rabadanov, M. H., Eldarov, E. M., Idziev, G. I. Development of industrial enterprises investment policy of Dagestan Republic // Ponte. 2017. Vol. 73. Is. 10. P. 317-325.

18. Tregenna, F. Manufacturing Productivity, Deindustrialization and Reindustrialization // UNU-WADER Working Paper. 2011. No. 57. 